\title{
CAPITAL, ESTADO E TRABALHO: UMA ANÁLISE DAS CONDIÇÕES DE TRABALHO DOS JOVENS INSCRITOS NO PROGRAMA PROJOVEM-TRABALHADOR EM SANTA CATARINA*
}

\author{
Gilberto Nogara Junior ${ }^{* *}$ \\ Mariléia Maria da Silva**
}

Resumo: Este artigo tem por objetivo analisar as condições de trabalho dos jovens oriundos de bairros periféricos em cidades catarinenses, objetivando problematizar a relação capital/Estado na crise capitalista, principalmente no tocante às políticas públicas destinadas a elevar a escolaridade e inserção profissional dos jovens considerados em "situação de vulnerabilidade social". Trabalhamos com a base dados fornecida pelo SINE, no qual tivemos acesso ao cadastro socioeconômico de 4.300 jovens, bem como oito entrevistas realizadas em duas cidades catarinenses.

Palavras-chave: Capital; Estado; Trabalho; Jovens.

Abstract: This article aims to analyze the working conditions of young people from outlying places in cities of Santa Catarina, aiming to discuss the relation capital/State in the capitalist crisis, especially with regard to public policies designed to raise the education and professional insertion of the young people considered in situation of social vulnerability. We work with the data base provided by SINE, where we had access to the socioeconomic records about 4.300 young, as well as eight interviews were carried out in two cities into Santa Catarina. 


\section{Introdução}

Se as pessoas acreditarem que estamos saindo da crise, elas vão agir como se estivéssemos mesmo já saindo. E aí sairemos mesmo. Esse é um ponto que as pessoas, em geral, entendem logo, mas não descobrem sozinhas. A previsão faz o futuro. Se as pessoas forem pessimistas, o futuro será ruim, porque elas vão se preparar para esse futuro ruim (SINGER). ${ }^{1}$

A frase acima aparentemente soa como se saindo de um livro de autoajuda que tivesse, por exemplo, o seguinte título - "Como sair da crise capitalista com a força do pensamento". No entanto, tais palavras foram proferidas pelo economista e Secretário Nacional de Economia Solidária do Ministério do Trabalho e Emprego (MTE), Paul Singer.

Contudo, não se pode substimar o poder ideologico que as palavras proferidas pelo referido economista carregam, sobretudo no período que vivemos, onde prevalece a enaltação do discurso empreendedorista, do "Tente outra vez" e do "Brasileiro não desiste nunca"2. Quando aqui utilizo a palavra ideologia uso-a nos termos de Mauro Iasi, quando este diz que "a ideologia pressupõe uma relação na qual a classe dominante expressa essa dominação em um conjunto de ideias; ideologia pressupõe inversão, velamento da realidade, naturalização das relações de dominação e, daí sua justificação" (IASI, 2011: p.81). Outro ponto importante de ser ressaltado na fala de Singer, reporta-se à individualização e responsabilização do sujeito pelo sucesso ou pelo fracasso, no caso, pela permanência ou não da crise.

O "otimismo-holístico-paranormal" do secretário vai contra até mesmo os relatórios produzidos por Organismos Nacionais (IBGE) e Internacionais (OIT) que apontam o acirramento da crise, atingindo de sobremaneira os jovens. Este ano o número 
de desempregados no mundo chegará a 200 milhões, mas pode chegar a 204 milhões se a desaceleração da economia se aprofundar e o crescimento mundial ficar abaixo de $2 \%$, informou a Organização Internacional do Trabalho (OIT, $2012)^{3}$. O número de trabalhadores com empregos vulneráveis globalmente em 2011 é estimado em 1,520 bilhão, um aumento de 136 milhões desde 2000 e de quase 23 milhões desde 2009 (OIT, 2012).

O mercado de trabalho brasileiro, como ocorreu na maioria dos países, sentiu os reflexos da crise internacional. Em relação a 2008 , houve aumento de $18,5 \%$ na população desocupada (de 7,1 para 8,4 milhões de pessoas), sobretudo entre os mais jovens, e crescimento da taxa de desocupação, de $7,1 \%$ para $8,3 \%$. A população ocupada, estimada em cerca de 92,7 milhões, não se alterou significativamente frente ao ano anterior (aumento de $0,3 \%$ ), e o nível de ocupação caiu de $57,5 \%$ para $56,9 \%$ (PNAD, 2009) ${ }^{4}$.

É nesta contradição que se inicia este artigo. De um lado um discurso que, aparentemente, beira a irracionalidade, mas que carrega em seu bojo uma arma ideológica disposta a obnubilar as relações que encerra, do outro lado, temos o acirramento de uma assim chamada "crise" que, segundo Fontes (2010), é o ponto a partir do qual se expandem as relações capitalistas. Desse modo irei analisar as condições de trabalho para os jovens oriundos de bairros periféricos em cidades catarinenses, objetivando problematizar a relação capital/Estado na assim denominada "crise" capitalista, principalmente no tocante às políticas públicas destinadas a elevar a escolaridade e inserção profissional dos jovens considerados em situação de "vulnerabilidade social". Com este fito utilizo a base de dados do $\mathrm{SINE} / \mathrm{SC}^{5}$, onde constam os dados de 4.300 jovens, com idades entre 17 e 30 anos, inscritos no Programa Nacional de Inclusão de Jovens - Projovem, na modalidade Projovem Trabalhador. 
Além destes dados, possuímos oito entrevistas realizadas com jovens durante a pesquisa "A inserção profissional dos egressos do Projovem-Trabalhador", em duas cidades catarinenses. Para realizar este intento este artigo segue estruturado da seguinte maneira: De Keynes a Hayek: diferentes épocas, diferentes interesses burgueses; Um peso, duas medidas: Estado máximo ou mínimo?; O Projovem-trabalhador e os jovens trabalhadores Catarinenses e, finalmente, algumas considerações finais.

\section{De Keynes a Hayek: diferentes épocas, diferentes interesses burgueses.}

De Keynes a Hayek, essa distinção serve para marcar as diferentes formas de pensamento e de atuação dos liberais burgueses na busca de preservar seus privilégios e "liberdades" alcançados no sistema capitalista. Além disso, esses teóricos liberais servem aqui para distinguir o modo de produção capitalista antes e depois da reestruturação do capital. O período Keynesiano foi marcado por forte intervenção Estatal, pelo Estado de Bem estar Social (Wellfare State) e pelo pleno emprego, até meados da década de 1970. Por sua vez, o período Hayekiano é marcado pelo desmonte do Estado de Bem-estar social, pela flexibilização das relações trabalhistas, e pelas ideias que embasam a prática do "terceiro setor", e, consequentemente, pelo esfacelamento dos direitos universais. Mesmo com ideias tão distintas, não se pode esquecer que os dois autores são liberais e, segundo Montaño (2008), dois aspectos garantem sua unidade de classe (burguesia), sendo a primeira "uma corrente de pensamento organizada em torno dos interesses de classe da burguesia; e em segundo lugar, consiste numa tradição centrada no conceito de liberdade. Ou seja, a ordem burguesa e a garantia de liberdades" (MONTANÕ, 2008: p.49). 


\section{JHON MAYNARD KEYNES}

"A guerra de classes me encontrará no meu lugar, o da burguesia esclarecida." (John Maynard Keynes).

John Maynard Keynes (1883-1946), nascido na Inglaterra, viveu os reflexos da depressão da década de 1880, passou pela primeira guerra mundial, crise de 1929 e pela segunda guerra mundial. Foram esses acontecimentos marcantes em seu pensamento e em sua prática política. Segundo Montanõ (2009) Keynes defendeu a política econômica de Estado intervencionista, utilizando-se de medidas fiscais e monetárias para amortizar os efeitos da crise, alavancar o capitalismo e acalmar a insatisfação popular.

Após a primeira guerra mundial e o crack da bolsa de Nova Iorque em 1929, caiu por terra à ilusão de que o capitalismo jamais entraria em recessão. Até então vigorava a ideia de que tudo aquilo que fosse produzido, naturalmente geraria sua demanda, conhecido como a 'Lei de Say'. A citada lei afirmava que "a demanda não é um limite para a produção, isto é, toda oferta cria sua própria demanda, assim qualquer quantidade de mercadorias produzidas encontra mercado, é solvável" (LUCHT, 2006: p.03). Essa lei auto-reguladora foi duramente criticada por Keynes quando este formula o 'Princípio da Demanda Efetiva' (PDE), presente no livro 'A Teoria Geral do Emprego, do Juro e da Moeda', publicado em 1936, afirmando que "a expectativa de demanda determina o produto" (BIELSCHIWSKY, 2011: p.64), em outras palavras, havendo pessoas para comprar as fábricas produziriam mais. Com isso Keynes procurou demonstrar que se não há empregos, não há demanda; e se não há demanda, aumenta o número de desempregados, o que acaba criando um círculo vicioso. Dessa maneira cabe ao Estado trazer para si a responsabilidade de salvaguardar o capitalismo reduzindo a taxa 
de juros e aumentando os gastos públicos, medidas estas que visavam aumentar a criação de empregos e, por consequência, o aumento das ofertas. Sendo assim, em períodos de crise o

livre mercado pode não gerar a demanda (ou consumo de mercadorias) suficientes para garantir o lucro dos capitalistas e o 'pleno emprego' dos trabalhadores', devido à redução de investimento na economia e ao aumento das poupanças (improdutivas) ou entesouramento"(MONTANÕ, ano: p.56).

O entesouramento se dava justamente quando aumentavam as incertezas e caiam às expectativas das vendas e dos lucros. A redução da taxa de juros visava estimular a aplicação do dinheiro "entesourado" na atividade produtiva, garantindo assim o aumento do capital circulante, geração de empregos e aumento no consumo. Ao reduzir a taxa de juros, reduz também às expectativas de lucro dos capitalistas em investimentos "entesourados", desse modo, para aqueles que querem ver seu dinheiro multiplicar-se, o investimento na atividade produtiva é o caminho apontado e defendido por Keynes. O aumento dos gastos públicos, incluindo-se aí grandes obras de infraestrutura, tinha por meta a criação de empregos, ainda que estas obras fossem de caráter "duvidoso", como afirma o referido autor,

em tempos de desemprego rigoroso, as obras públicas, ainda que de duvidosa utilidade, podem ser altamente compensadoras [...]; porém a validade desta proposição torna-se cada vez mais contestável à medida que nos aproximamos do pleno emprego" (KEYNES, 1996, p. 143).

A busca pelo pleno emprego, que marcou o período Keynesiano, tinha por objetivos, além de aumentar o consumo, 
diminuir o descontentamento com o capitalismo naquele delicado momento, por isso visava "diminuir a insatisfação e a disposição de luta dos trabalhadores, e como forma de potenciar a produção e o consumo das massas mediante seu salário" (MONTANÕ, 2008: p.59). É preciso ressaltar que o período pós-guerras foi fortemente marcado pelas

mobilizações sindicais e partidárias dos trabalhadores que, em torno de reivindicações sociais legítimas, pressionaram a incorporação, pelo capital, do atendimento de parte das suas necessidades sociais, operando mudanças nas legislações trabalhistas e nas medidas de proteção social. Essa conjunção de fatores foi responsável pela constituição do Welfare State, que se tornou um dos principais pilares de sustentação institucional daquela fase expansiva do capitalismo, ao integrar à sua dinâmica econômica parte das demandas operárias por melhores condições de vida e trabalho" (MOTA, 2009: p.6).

Portanto, o que tivemos no período marcado pela influência do pensamento Keynesiano foi à assunção, por parte do Estado, na condução das revoltas trabalhistas e de medidas que possibilitassem ao capital se reestruturar. Em outros termos, por um lado o Estado mitigou os efeitos da crise procurando garantir o pleno emprego e, por consequência, o aumento do consumo, e por outro lado, reduziu o lucro dos capitalistas (taxa de juros) forçando-os a investir na cadeia produtiva. Foram essas as medidas que impulsionaram a expansão capitalista no período pós-guerra, quando, segundo Harvey (2009, p. 125),

o Estado teve de assumir novos (keynesianos) papéis e construir novos poderes institucionais; o capital corporativo teve de ajustar as velas em certos aspectos 
para seguir com mais suavidade a trilha da lucratividade segura; e o trabalho organizado teve de assumir novos papéis e funções relativos ao desempenho nos mercados de trabalho e nos processos de produção. $\mathrm{O}$ equilíbrio de poder, tenso mas mesmo assim firme, que prevalecia entre o trabalho organizado, o grande capital corporativo e a nação-Estado, e que formou a base de poder da expansão de pós-guerra.

\section{FREDERICK AUGUST VON HAYEK.}

"O livre mercado é o único mecanismo que já foi descoberto para o alcance da democracia participativa." (FRIEDMAN) ${ }^{7}$.

Frederick August von Hayek (1899-1992), nascido em Viena (Aústria), economista liberal é considerado o pai do neoliberalismo. Para Hayek as únicas funções inerentes ao Estado são: prover uma estrutura para o mercado e prover os serviços que o mercado não pode fornecer (MERQUIOR,1991 apud MONTANÕ, 2008: p.81). Em 1944 publicou o livro "O caminho da servidão" (The road to serfdom), onde criticava abertamente o intervencionismo estatal, alegando que isso levaria ao totalitarismo e, consequentemente, à perda da liberdade. Para Hayek só há liberdade e possibilidade de prosperidade no mercado concorrencional, ou seja, termos como justiça social, igualdade de oportunidades, seguridade social e planejamento estatal configuaram graves entraves ao pleno desenvolvimento da liberdade. Portanto, somente a economia regida pelo mercado apresentaria as condições favoráveis as florescimento da liberdade, ou seja, quando "há economia de mercado, o indivíduo tem a liberdade de escolher qualquer carreira que deseje seguir, de escolher seu próprio 
modo de inserção na sociedade" (MISES, 2009: p.21). A frase epígrafe no início dos escritos pertence do estadunidense Milton Friedman (1912-2006), amigo e parceiro intelectual de Hayek, e explica melhor do que ninguém o pensamento Hayekiano, pois somente a concorrência de mercado seria capaz de estimular o desenvolvimento social. Hayek (1990, p.63) considera a

concorrência um método superior, não somente por constituir, na maioria das circunstâncias, o melhor método que se conhece, mas, sobretudo por ser o único método pelo qual nossas atividades podem ajustar-se umas às outras sem a intervenção coercitiva ou arbitrária da autoridade. Com efeito, uma das principais justificativas da concorrência é que ela dispensa a necessidade de um 'controle social consciente' e oferece aos indivíduos a oportunidade de decidir se as perspectivas de determinada ocupação são suficientes para compensar as desvantagens e riscos que a acompanham.

Segundo Montanõ (2009) Hayek não somente aceita a desigualdade, como também a defende, alegando ser a desigualdade um mecanismo natural, promovendo o desenvolvimento social e econômico. Dentro do pensamento Hayekiano a justiça social levaria os indivíduos a se acomodarem, enquanto as desigualdades os fariam moveremse. Esta crítica endereçava-se de modo candente ao Estado de Bem-estar-social (Wellfare State). Em uma tacada só, o aludido autor procura eliminar qualquer possibilidade de planejamento estatal centralizador e, ainda por cima, coloca a desigualdade como motor do desenvolvimento econômico. É curioso notar como os autores liberais procuram naturalizar o mercado concorrencional, Friedman alega ser o único mecanismo que já foi "descoberto", tal qual uma jazida de diamantes que estivesse a espera de garimpeiros. Hayek, por sua vez, alega ser 
a desigualdade um mecanismo "natural". No entanto o mercado concorrencional não elimina a necessidade de um governo, pelo contrário, destina a ele algumas atribuições , entre elas,

um governo é essencial para a determinação das "regras do jogo" é um árbitro para interpretar e pôr em vigor as regras estabelecidas. O que o mercado faz é reduzir sensivelmente o número de questões que devem ser decididas por meios políticos - e, por isso, minimizar a extensão em que o governo tem que participar diretamente do jogo. (FRIEDMAN) ${ }^{8}$.

Outra questão pertinente a ser ressaltada é: se não é o Estado, quem deverá encarregar-se de políticas sociais ? Segundo Hayek "o governo só deveria intervir em caso de catastrófes e calamidades, de modo a garantir a todos um mínimo suficiente para conservar a saúde e a capacidade de trabalho" (Hayek, 1990, p. 143). Por sua vez, Friedman afirma que "o mais desejável - é a caridade privada" (Friedman, s/d, p.99). Perceba que no pensamento de Hayek o Estado só deve intervir em casos de calamidades, de emergências, devendo manter a capacidade de trabalho, ou seja, manter minimamente alguma alimentação, abrigo e vestimentas. A atuação do Estado reporta-se apenas a "possibilidade de intervenção estatal, não constituindo, portanto um direito" (MONTANÕ, 2008: p.64). No entanto, o pensamento de Friedman é o que mais se aproxima da nossa atualidade, marcada pelas políticas neoliberais e pela atuação das ONG's, das associações filantrópicas, entidades confessionais e similares, tema a ser tratado nas seções seguintes.

\section{Um peso, duas medidas: Estado máximo ou mínimo?}

Nesta seção do artigo utilizo da expressão atribuída a Sócrates "um peso, duas medidas" para mostrar que sendo 
máximo ou mínimo quem ganha é o capital. Grosso modo, esta frase significa ter condutas distintas diante de situações idênticas. As situações idênticas referem-se às "crises" do capital, sendo as condutas distintas o papel desempenhado pelo Estado em cada uma delas. Como vimos anteriormente, o período Keynesiano foi marcado por forte intervenção Estatal, período este conhecido como Wellfare State. Por sua vez, o período Hayekiano é marcado pelo desmonte do Estado de Bem-estar social e pela implementação da livre concorrência como motor do desenvolvimento. De todo modo cabe mais uma vez ressaltar que

liberalismo e o neoliberalismo são formas de defesa do modo de produção capitalista. A forma neoliberal encontra terreno para o seu desenvolvimento nas transformações econômicas e políticas do capitalismo, que, após o relativo restabelecimento do processo de acumulação pelo Estado 'Keynesiano' (Estado de bemestar social), segue sua tendência de concentração e centralização" (FIORI, 1997 apud COUTINHO, 2011: p, 94).

Dessa maneira a crise capitalista do início do século $\mathrm{XX}$ foi salvaguardada por um Estado intervencionista nos moldes Keynesianos; Hoje a crise capitalista requer um Estado intervencionista aos moldes neoliberais. No primeiro, uma maior atuação do Estado, no segundo, uma atuação focalizada, ou seja,

ação estatal no atendimento das necessidades sociais básicas, reduzindo a área de atuação do Estado por meio de três mecanismos: a privatização, a publicização (transferência da gestão de serviços e atividades para o setor público não-estatal) e a terceirização (RIZZOTTO, 2009, p. 01) . 
Se ao Estado a ordem nos dias atuais é "focalizar, descentralizar, privatizar" (COUTINHO, 2009, p, 99), quem ganha com isso? O capital! Quando no período Keynesiano as ordens foram: redução das taxas de juros, aumento nos gastos públicos e o pleno emprego, quem ganhou com isso? O capital! Porém não devemos esquecer as árduas conquistas trabalhistas que foram asseguradas no Estado do período Keynesiano; o que fez o capital, nos termos de HARVEY (2009, p. 125) "ajustar as velas em certos aspectos para seguir com mais suavidade". Em outras palavras, mínimo ou máximo o que se evidencia é a intrínseca relação capital-Estado. Relação esta definida por MÉSZÁROS (2011) como:

o sistema sociometabólico do capital tem seu núcleo central formado pelo tripé capital, trabalho assalariado e Estado, três dimensões fundamentais e diretamente inter-relacionadas, o que impossibilita a superação do capital sem a eliminação do conjunto dos três elementos que compreendem esse sistema" (MÉSZÁROS, 2011: p, 11).

O outro pilar do sistema sociometabólico apontado por MÉSZÁROS é o trabalho assalariado, sendo este o responsável direto pela extração de mais-valor. Neste sentido o Estado ao "focalizar, descentralizar e privatizar" (COUTINHO, 2011: P.83) age de acordo com as premissas neoliberais que, segundo Gentili (1996, p. 09), é preciso compreendê-las como

um complexo processo de construção hegemônica. Isto é, como uma estratégia de poder que se implementa sentidos articulados: por um lado, através de um conjunto razoavelmente regular de reformas concretas no plano econômico, político, jurídico, educacional, etc. e, por ou através de uma série de estratégias culturais orientadas 
a impor novos diagnósticos acerca da crise e construir novos significados sociais a partir dos quais legitimar as reformas neoliberais como sendo as únicas que podem (e devem) ser aplicadas no atual contexto histórico de nossas sociedades.

No Brasil o "neoliberalismo" foi introduzido associado ao discurso da necessidade de modernização do país, que se iniciou no governo de Fernando Collor de Mello, em 1989, e se aprofundou nas décadas de 1990 e 2000" (RIZZOTTO, 2009 , p. 01). No tocante às políticas sociais o neoliberalismo as compreende como assistencialismo e não como direitos, conforme o pensamento dos teóricos liberais analisados nas seções anteriores, assim sendo a atuação estatal

deve ser focalizada nos pobres, e a sociedade, na figura das organizações não-governamentais e no voluntariado, que deve ser estimulada a assumir responsabilidades pela resolução dos seus problemas, reduzindo a carga imposta ao Estado ao longo do tempo" (RIZZOTTO, 2009, p. 01).

Inserir a discussão acerca do terceiro setor, (Montaño, 2008) dentro do processo de reestruturação do capital, no interior e como resultado, faz-se necessário para compreender o novo trato a questão social. O termo organização não governamental (ONG), de acordo com COUTINHO (2011) foi cunhado pela ONU (Organização das Nações Unidas), no ano de 1940, e inicialmente designava entidades que executavam projetos humanitários e de interesse público. Hoje temos uma variada gama de "instituições", nos moldes das ONGs, como por exemplo, Organização da Sociedade Civil, Organização sem Fins Lucrativos, Entidade Filantrópica, Entidade Assistencialista, Organização da Sociedade Civil de Interesse Público, Entidade 
de Utilidade Pública e Organização Social. De 1940 até os dias atuais o termo ONGs popularizou-se, tornam-se popularmente conhecidas no Brasil "principalmente durante a década de 90, com o grande impulso proporcionado pela ECO-92, dando maior visibilidade a esses tipos de associação" (CAMPAGNAC, 2006: p.02). No ano de 2010, segundo o IPEA (Instituto de pesquisa economica aplicada) foram repassados as OSCs (Organizações da Sociedade Civil) R \$ 4,1 bilhões, o que representa cerca de $0,48 \%$ do PIB brasileiro. De acordo com os números de 2005 presentes no IBGE

estavam registradas 338 mil Fundações Privadas e Associações sem Fins Lucrativos, que empregavam 1,7 milhão de pessoas em todo o País, com salários médios mensais de $\mathrm{R} \$ 1.094,44$. O tempo médio de existência dessas instituições era de 12,3 anos e o Sudeste abrigava $42,4 \%$ delas. Essas instituições são, em geral, de pequeno porte, e 79,5\% (268,9 mil) delas não possuem sequer um empregado formalizado" (IBGE, 2011).

Ainda segundo o IBGE entre 1996 e 2002 cresceu 157\% o número de instituições desse perfil, e ao todo foram postos para trabalhar 1,7 milhões de pessoas, sendo a esmagadora maioria mão de obra voluntária. De acordo com Ipea ${ }^{10}$, "as estimativas não oficiais são de que no Brasil, hoje, atuem aproximadamente 20 milhões de voluntários, o que equivale a 13 vezes o número de funcionários registrados no setor".

Ao voltarmos o pensamento às pressões trabalhistas que marcaram o período Keynesiano, vimos que os direitos trabalhistas foram assegurados no Estado, mesmo este sendo parte do sistema sociometabólico. Naquele período (Montanõ, 2008) o Estado "intervencionista" Keynesiano utilizou-se de "medidas fiscais" e "monetárias"” para amortizar os efeitos da crise, alavancar o capitalismo e acalmar a insatisfação popular. 
Atualmente as politicas neoliberais vem corroendo direitos até então assegurados pelo Estado, e em seu lugar a proliferação de ONGs e similares

contribuem com a politica do 'colchão amortecedor', para amenizar os conflitos e contradiçoes de classes[...] a participação do voluntariado transforma a solidariedade, própria das práticas sociais das classes populares, em mais um mecanismo institucionalizado de exploração de classe" (COUTINHO, 2011: p, 83).

Nessa toada o neoliberalismo "propõe um Estado mínimo em sua obrigação econômica, mas que, para Pablo Gentili (1996), trata-se concomitantemente de um Estado máximo na política" (NOZAKI, 2011).

\section{O Projovem-trabalhador e os jovens trabalhadores} Catarinenses.

\footnotetext{
"Se quiserdes que os caseiros trabalhem, diziam eles, conservai-os na pobreza". ${ }^{11}$
}

Nesta seção resumiremos em primeiro lugar o que é o Programa Nacional de Inclusão de Jovens (Projovem), em destaque a modalidade Projovem-Trabalhador. Em seguida analisaremos a base de dados fornecida pelo SINE-SC, no qual tivemos acesso ao cadastro socioeconômico de 4.300 jovens, bem como oito entrevistas realizadas com durante a pesquisa "inserção profissional dos egressos do Projovem-Trabalhador", em duas cidades catarinenses, problematizando as reais condições que se encontram esses jovens.

O Programa Nacional de Inclusão de Jovens (Projovem), instituído pela Lei $n^{\circ} 11.129$, de 30 de junho de 2005, regido a partir de 10 de janeiro de 2008 pela Lei $n^{\circ} 11.692$, de 10 de 
junho de 2008, e regulamentado pelo Decreto $n^{\circ} 6.629$, de 04 de novembro de 2008, é composto por quatro modalidades, a saber: Projovem Adolescente - Serviço Socioeducativo; Projovem Urbano; Projovem Campo Saberes da Terra e Projovem Trabalhador. O Programa destina-se aos jovens entre 15 a 29 anos, com o propósito de propiciar a sua reintegração ao processo educacional, bem como promover sua qualificação profissional e o desenvolvimento humano (BRASIL, 2008a). ${ }^{12}$ A modalidade Projovem Trabalhador, foco de nosso interesse, segundo o Art. 37.:

tem como objetivo preparar o jovem para ocupações com vínculo empregatício ou para outras atividades produtivas geradoras de renda, por meio da qualificação social e profissional e do estímulo à sua inserção no mundo do trabalho" (BRASIL, 2008b).

E divide-se em quatro submodalidades: Consórcio Social da Juventude; Juventude Cidadã; Escola de Fábrica e Empreendedorismo Juvenil. Os requisitos para o ingresso são: ter idade de 18 a 29 anos, possuir um renda per capita de até um salário mínimo e estar "cursando ou tenha concluído o ensino fundamental; cursando ou tenha concluído o ensino médio, e não esteja cursando ou não tenha concluído o ensino superior ${ }^{13}$ ", (BRASIL, 2008b). ${ }^{14}$

Os jovens inscritos no Projovem Trabalhador recebem um auxílio financeiro de $\mathrm{R} \$ 600,00$, divididos em 06 parcelas de $\mathrm{R} \$ 100,00$. Devem frequentar um curso de qualificação social e profissional com carga horária de trezentas e cinquenta horas, sendo obrigatória a frequência mínima de 75\%. Cabe ainda ressaltar que as entidades responsáveis por qualificar estes jovens foram selecionadas mediante chamada pública e o governo exige que $30 \%$ dos jovens inscritos no programa sejam encaminhados (sob as mais variadas formas, como estágios, 
aprendizes, contratos e carteira assinada) ao mercado de trabalho, conforme estabelece o Art. 46.: "[...]fica estabelecida a meta mínima de trinta por cento" (BRASIL, 2008b).

De posse da base de dados do SINE-SC tivemos acesso ao cadastro socioeconômico de 4.300 jovens, deste montante fizemos o recorte de $30 \%$ ou seja, 1239 jovens cadastrados, o que nos propiciou uma análise mais minuciosa. Os cadastros apontam indicativos pertinentes para analisarmos as condições que esses jovens são "qualificados" e "encaminhados" ao mercado de trabalho. De acordo com dados analisados constatamos que $51,39 \%$ desses jovens têm entre 18 e 22 anos de idade. Além disso, 77\% deles têm naturalidade catarinense, seguido de $10 \%$ nascidos no Paraná e 4,5\% no Estado do Rio Grande do Sul. Cabe ressaltar que a maioria desses jovens mora em bairros periféricos. Outro ponto de suma importância sobre estes jovens pode ser observado quando cruzamos os dados presentes nos seguintes gráficos: Situação na Família (gráfico 01) e Situação no mercado de Trabalho (gráfico 02).
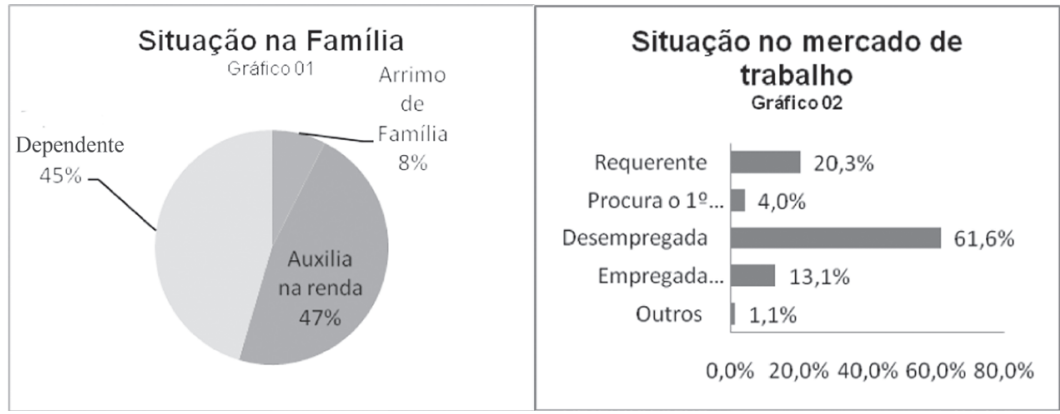

No gráfico 01 constata-se que $8 \%$ ou 104 jovens são arrimos de família. O termo arrimo faz alusão àquele que sustenta a maior parte dos gastos familiares. Os que auxiliam na renda familiar correspondem a 47\% ou 611 jovens. Ao juntar àqueles que são arrimo aos que auxiliam na renda, vemos que $55 \%$ ou 715 
jovens contribuem com a renda familiar. A situação se mostra critica quando analisamos a situação desses jovens no mercado de trabalho. No gráfico 02 , pode-se ver que $86,9 \%$ ou 1.131 jovens estão desempregados, são requerentes (solicitantes), estão à procura do primeiro emprego ou ainda trabalhando no mercado informal. Algumas suposições podem ser feitas com base nos números acima destacados. Dos 1239 jovens, 1131 estão desempregados, porém 715 afirmaram auxiliar na renda. Se levarmos em consideração os $45 \%$ ou 585 jovens dependentes e somar aos $13,1 \%$ ou 170 jovens que afirmaram ter emprego com carteira assinada, têm-se $58 \%$ ou 745 jovens. Desse modo sobram $42 \%$ ou 545 jovens que contribuem com a renda familiar, o que nos permite pensar que para sobreviverem e auxiliarem na renda esses jovens trabalham na informalidade, vivendo de "bicos" e trabalhos sazonais, em outras palavras, trabalham sem qualquer direito trabalhista. Essa hipótese encontro força no gráfico 03 Renda do grupo familiar:

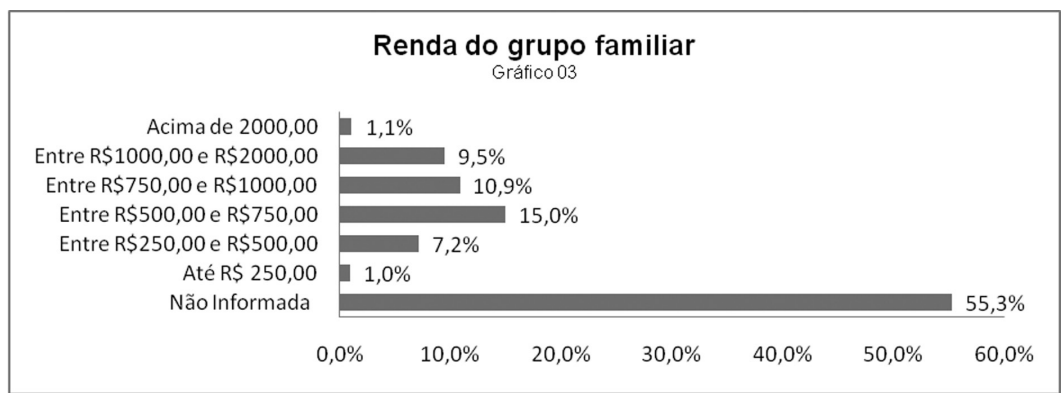

Neste gráfico consta que 55,3\% ou 719 jovens não informaram a renda familiar. O que também nos permite pensar que talvez não seja possível estabelecer uma renda familiar pelo fato dos trabalhos realizados por esses jovens serem sazonais, de bicos ou ainda que a renda não seja uma constante. Ademais constatamos que a renda familiar de $42,62 \%$ ou 554 jovens orbita entre $\mathrm{R} \$ 250,00$ e R $\$ 2.000,00$. Na base de dados analisada não 
consta nenhuma informação sobre o número de pessoas que compõem as famílias desses jovens. Se levarmos em conta os dados do censo 2010 do IBGE $^{15}$, a média da família brasileira e de 3,4 pessoas. Desse modo se pegarmos os dados extremos do gráfico 03 teremos famílias que tem por renda média o valor de $\mathrm{R} \$ 2.000,00$, que ao dividir por 3,4 (número de pessoas na família) equivale a $R \$ R \$ 588,00$ por pessoa. Observando o outro extremo dos dados a situação fica desesperadora, como o exemplo das 13 famílias que tem por renda média a quantia de $\mathrm{R} \$ 250,00$, que dividir por 3,4, equivale a $\mathrm{R} \$ 73,52$ por pessoa. Porém ao focar nossa análise nos $25 \%$ que têm por renda familiar a média de $\mathrm{R} \$ 800,00$ e dividir por 3,4, teremos o resultado de $\mathrm{R} \$ 235,29$ per capta. Se dividir a quantia de $\mathrm{R} \$ 235,29$ por 30 (número de dias do mês) equivale a $\mathrm{R} \$ 7,86$ por dia. Algumas referências podem balizar o tamanho da agonia de sobreviver com a quantia diária mencionada, como por exemplo, o preço do ônibus em Florianópolis/SC ${ }^{16}$.

Ao cruzar os dados presentes nos gráficos 04 e 05, Escolaridade e Pretensão Ocupacional (marcada como $1^{\mathrm{a}}$ opção), respectivamente, nos permite fazer algumas elucubrações pertinentes.

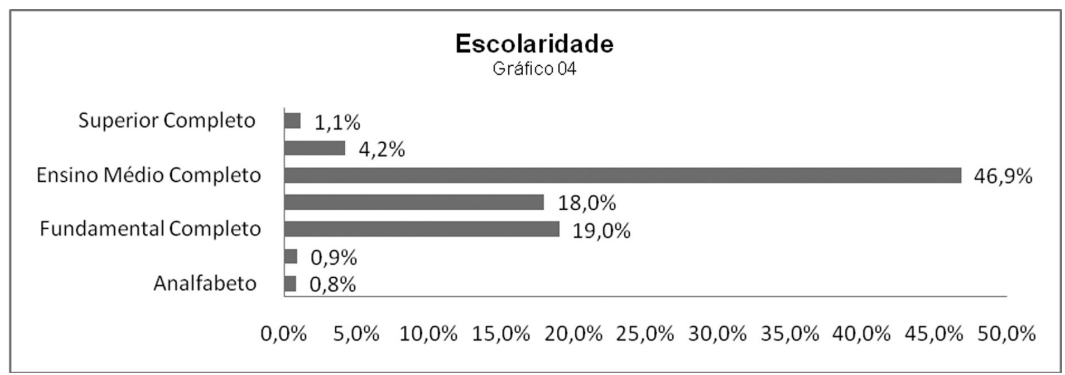

O número de jovens que concluíram o ensino fundamental gira em torno de $89,2 \%$ ou 1.159 jovens. No entanto ao ter por parâmetro a conclusão do ensino médio, obtêm-se $52,2 \%$ ou 
678 jovens com este grau de escolaridade. Os jovens analfabetos correspondem a $0,8 \%$ ou 10 pessoas. Como apontam os dados, é realidade a "quase" universalização do ensino fundamental e que para $52,2 \%$ dos jovens é realidade a conclusão do ensino médio. Cerca de 51,39\% desses jovens têm entre 18 e 22 anos de idade, assim sendo é grande a probabilidade de terem concluído o ensino fundamental entre a segunda metade dos anos 1990 e inicio dos anos 2.000. Essa "quase" universalização do ensino fundamental e os mais de 50\% que concluíram o ensino médio se tratam de transformações que marcaram os anos 1990 e que visavam possibilitar

competências e conhecimentos gerais, essenciais para o mercado de trabalho e para a construção da cidadania, como comunicação verbal e escrita, leitura e compreensão de textos, raciocínio, saúde e segurança no trabalho, preservação ambiental, direitos humanos, informação e orientação profissional e outros eventuais requisitos para as demais habilidades (BRASIL, 1999, p.8) $)^{17}$.

Em outras palavras, preparados para o trabalho simples na sociedade capitalista. Segundo Lima, Neves, Pronko (2009) ${ }^{18}$ "do ponto de vista do capital, a formação para o 'trabalho simples' destina-se à preparação técnica e ético-política da mão-de-obra, visando a aumentar a produtividade do trabalho sob a direção capitalista". Ou seja, passaram a exigir um patamar mínimo de escolarização para a realização do trabalho simples, pautado, sobretudo na aquisição de habilidades de leitura e escrita.

Nesse sentido ao lançar o olhar sobre o gráfico 05 sobre a Pretensão Ocupacional constatamos que muitos jovens, cerca de 218 , responderam que não possui qualquer tipo de pretens que, daqueles que responderam qual a sua, 218 jovens não possui qualquer pretensão ocupacional, o que nos permite 
pensar que aceitam qualquer "oportunidade" que venha a surgir. Na sequência das pretensões, optaram por atendente e recepcionista 108 jovens; vendedor foi opção de 88 jovens e auxiliar administrativo com 84 opções assinaladas pelos jovens.

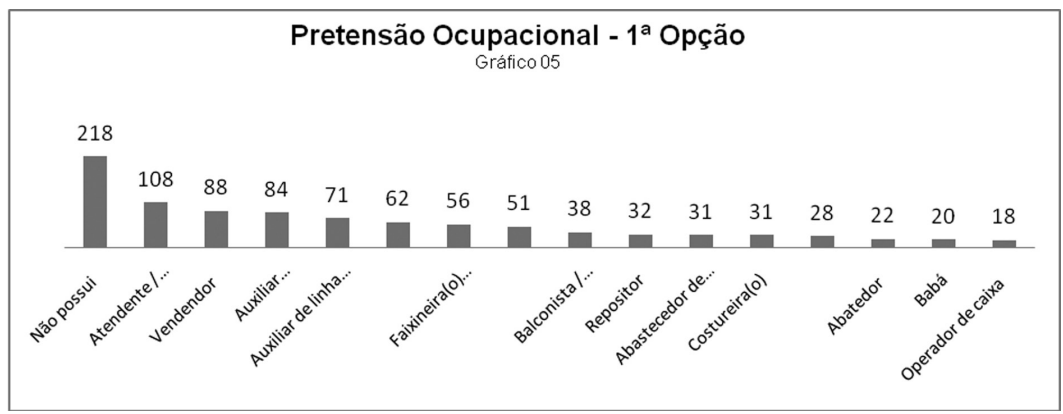

As funções citadas nas últimas duas linhas exigem dos trabalhadores além dos rudimentos da leitura e da escrita, boa comunicação, de modo a poderem atender os consumidores, anotar recados e calcular valores. Em entrevista $\operatorname{Rosa}^{19}, 22$ anos, moradora de Porto União-SC, refere-se a aulas do Projovemtrabalhador da seguinte maneira:

Era tipo, uma aula normal, igual uma aula de uma escola, a professora de matemática passava as contas de dividir, pois tinha gente que tinha só a terceira série do ensino fundamental. Tinha pessoas que não sabiam fazer conta então a professora ensinava a divisão, às porcentagens. Teve a professora de Português que ensinou a nova ortografia, ensinou o que é fazer uma redação, o professor de Recursos Humanos ensinou como fazer um currículo, como se comportar em uma entrevista. E o de informática ensinou o básico na área de informática, ensinou a mexer no teclado, no mouse, na internet, os programas que podem ser baixado na internet. (ROSA). 
Além dos rudimentos de funções básicas aprendidas na escola o Projovem-trabalhador carrega consigo mais um nocivo ingrediente, típico dos discursos neoliberais que colocam a culpa do sucesso ou do fracasso ao individuo, como aponta RUMMERT (2009) sobre o movimento que transfere à classe trabalhadora a responsabilidade de qualificar-se como maneira de superar condições de adversidade. Esse discurso atua de maneira ideológica nos jovens entrevistados, sendo possível perceber a "esperança" no discurso qualificador como trampolim para o sucesso, conforme a fala de Lola, moradora de Porto União/ SC, quando esta diz:

Paciência né, se não sair (o emprego) a gente tenta outros cursos que vem por aí né? Eu faço curso de cabeleireira também[...] eu terminei o de costura e comecei o de cabeleireira, porque também a gente não pode ficar parada sabe, já faz tempo, até agora não chamaram, então a gente vai tentando outras coisas até que uma dê certo (LOLA).

Ainda sobre o discurso qualificador como tábua de salvação para os jovens pobres, não posso me furtar da entrevista concedida pelo Ernesto, 27 anos, natural de Florianópolis, quando este traça um paralelo, baseado em suas experiências trabalhistas, sobre o mercado de trabalho e a exploração sofrida por falta qualificação,

vendo que quando tu não tinhas uma instrução muito boa, eles (mercado) exploravam mesmo essa questão. E quando eles viam que tu tinha uma instrução educacional boa eles não te exploravam pelo meio de conhecimento mas exploravam pela questão da mão de obra. Tipo: 'Ah! tu pode fazer isso aqui e isso aqui não sei o que...' Faziam tipo um jogo sentimental pra 
tu trabalhar. E quando tu ia pedir algum favor, pedir algum direito teu, parecia que tu tava pedindo um favor assim. Então se via bem isso, e eu, uma das coisas que eu aprendi no mercado é assim, quanto mais qualificado você tiver mais você vai poder ir, exigir e bater de frente com a instituição, em si. Porque se assim não for ele (mercado) te explora literalmente e muito. Por isso que eu aprendi pelo menos vivenciando no trabalho, e eu sofri bastante pra aprender isso também, sofri bastante mesmo[...]não ser um profissional bem formado você é muito explorado, você não tem uma garantia que vai ficar no emprego e o teu salário é muito baixo. Não é compatível com todo esforço que você se dedica na empresa. Além de te causar muitas lesões no teu corpo também porque geralmente acontece isso, que foi o que aconteceu comigo também (ERNESTO).

Como vimos nos dados, o ensino médio completo é realidade a 52,2\% ou 678 jovens. Isso demonstra que no Estado de Santa Catarina a universalização do ensino médio está longe de realidade. Além disso, vimos que $55 \%$ ou 715 jovens contribuem com a renda familiar ou são arrimo. Isso nos mostra que esses jovens são lançados ao mercado de trabalho com baixa escolarização. Por sua vez, a baixa escolarização "permite" a esses jovens ocupar postos de trabalho que os remuneram parcamente, que por sua vez, possibilita apenas sua existência, deixando-os enredados numa perversa trama.

\section{Considerações finais}

Acima busquei problematizar as condições que esses jovens egressos do Projovem-trabalhador em Santa Catarina se encontram, para tanto me utilizei de dados e falas que atestam suas condições econômicas, ideológicas, escolaridade e anseios 
pessoais. Cabe mencionar ainda que o Projovem-trabalhador foi implementado na gestão de Luiz Inácio Lula da Silva, Partido dos Trabalhadores (PT) dando continuidade às políticas neoliberais iniciada no início dos anos 1990 e sendo continuada pelo governo de FHC. Do período de FHC até o segundo mandato de Lula, o repasse de verba feito pelo governo federal a entidades sem fins lucrativos, incluindo ONGs, passou de R\$ 2,244 bilhões em 1999 para R \$ 4,106 bilhões em 2010, segundo dados do IPEA (Instituto de Pesquisa Econômica Aplicada). ${ }^{20}$ Assim sendo o governo Lula da Silva repassou R\$ 1,862 bilhões a mais que o governo de FHC. De acordo com o jornal O Estado de São Paulo ${ }^{21}$, em 2010 o ministério da Educação teve R\$ 1,28 bilhão a menos para gastar em 2010. Trágica coincidência.

Outro ponto a ser explorado refere-se a quantia de $\mathrm{R} \$ 600,00$ (dividido em seis parcelas de $\mathrm{R} \$ 100,00$ ) dada aos jovens que participam do Projovem-trabalhador. Ao retomar os dados que mostram a renda média de $\mathrm{R} \$ 800,00$ para $25 \%$ dos jovens e dividir por 3,4 (números de pessoas na família) e dividir novamente por 30 (dias do mês) sobram apenas $\mathrm{R} \$ 7,86$ per capta/dia. Se colocar mais $\mathrm{R} \$ 100,00$ na renda familiar desses jovens a renda per capta/dia sobe para $\mathrm{R} \$ 8,82$. A primeira vista pode parecer insuficiente ou até mesmo irrisória tal quantia para àqueles que nunca passaram por tamanho apuro. Porém para quem é pobre qualquer dinheiro a mais faz diferença. Essa diferença de valores atrelada ao discurso massivo da qualificação como tábua de salvamento contribuem, nos termos de COUTINHO (2011) "com a politica do 'colchão amortecedor”. Em outras palavras, a insatisfação popular é atenuada no campo ideologico, como o discurso qualificador cheio de esperança, conforme percebe-se na entrevista de Lola (Porto União/SC) e no campo financeiro, onde qualquer real a mais significa pelo menos dois ou três pães a mais na mesa.

Ademais pode-se constatar que a escolarização, que é um 
direito garantido pelo Estado, se dá pelos mais diversos motivos, de forma parcial e precarizada. Assim sendo o Estado por meio de políticas neoliberais repassa verbas a ONGs e similares para dar a esses jovens àquilo que a escola não deu, ou seja, os rudimentos básicos para exercerem o trabalho simples no capitalismo. Esse movimento ilustra com detalhes as políticas neoliberais em ação. Enquanto a expropriação primária conquistou "a terra para a agricultura capitalista, incorporaram o solo ao capital e entregaram à indústria das cidades os braços dóceis de um proletariado sem lar nem pão" (MARX, 2009: p.46). As expropriações secundárias Fontes (2010) visam o desmantelamento dos direitos sociais e trabalhistas, de modo a reduzir os custos e aumentar os lucros, em outras palavras, a extração do mais-valor aumenta na medida em que os direitos trabalhistas diminuem. Outra peripécia do capital em tempos de crise, que ALVES (2012) ${ }^{22}$ define como captura de subjetividades, onde

sob o capitalismo global, os jovens proletários mais qualificados, empregados ou desempregados, estáveis ou precários, tornam-se hoje objetos privilegiados de "captura" da subjetividade do trabalho pelo capital, sendo expostos de modo candente à manipulação pelo capital no plano das experiências expectantes, isto é, experiências que organizam (ou manipulam) anseios, expectativas e utopias pessoais. O traço estrutural do capitalismo global é a manipulação da subjetividade do homem-que-trabalha. Por isso, o capitalismo global, ou seja, o capitalismo histórico na fase de crise estrutural do capital é essencialmente o capitalismo manipulatório. A exacerbação da dimensão manipulatória do capital decorre da própria natureza da dinâmica de acumulação capitalista. 
Dessa maneira é possível perceber que até mesmo as expectativas e anseios são fisgados e manipulados, como no caso citado no início deste escrito, onde o economista-político Singer prega "o basta acreditar que sairemos da crise", ou no caso de jovens desempregados expostos ao discurso massivo que atrela qualificação a garantia de sucesso empregatício e superação da condição precária, como bem aponta Rummert (2009, p.210) sobre o movimento que transfere para

a classe trabalhadora a responsabilidade por qualificar-se de modo a superar, em curto prazo de tempo, e de forma adequada às necessidades do modelo socioeconômico, a situação de destituição de direitos, bem como a decorrente precarização da vida, ambas derivadas das próprias características estruturais do modo de produção capitalista.

Ora, percebe-se agora que a contradição inicial se descortina, o discurso responsabilizador/culpabilizador, é uma arma ideológica a serviço do capital em tempos neoliberais que acerta milhares de cabeças de jovens trabalhadores e desempregados, ocultando as relações econômicas responsáveis pela precarização do trabalho e do trabalhador e inculcando-lhes uma falsa promessa de superação, mantendo-os num círculo de precariedade.

\section{Notas}

*Trabalho apresentado no $22^{\circ}$ seminário de integração científica da Universidade do estado de Santa Catarina - UDESC.

${ }^{* *}$ Acadêmico do Curso de Pedagogia - FAED-UDESC, bolsista de iniciação científica (PIBIC/UDESC) - gilrassico@gmail.com

${ }^{* * *}$ Orientadora da pesquisa "Egressos do projovem-trabalhador em Santa Catarina", Professora do Departamento de Ciências Humanas, do Centro de 
Ciências Humanas e da Educação, FAED/UDESC - marileiamaria@hotmail. com.

${ }^{1}$ Disponível em: <http://agenciabrasil.ebc.com.br/noticia/2009-04-20/ economia-solidaria-pode-ser-saida-para-crise-afirma-paul-singer $>$. Acesso em: 13 abr. 2012. 15:17:20.

${ }^{2}$ Estas campanhas divulgadas massivamente nas mídias atuam no sentido aumentar a auto-estima daqueles que são explorados, em outras palavras, se você mora mal, come mal e trabalha muito, não desanime, pois Brasileiro não desiste nunca. Está desempregado e cansado de procurar emprego? Tente outra vez. Se tentares e não conseguires, vire empreendedor.

${ }^{3}$ Disponível em: $<$ http://www.onu.org.br/mundo-enfrenta-desafio-de-criar600-milhoes-de-postos-de-trabalho-adverte-oit/>. Acesso em: 21 mai. 2012. 13:19:46.

${ }^{4}$ Disponível em: $<$ http://www.ibge.gov.br/home/presidencia/noticias/noticia visualiza.php?id_noticia=1708>. Acesso em: 22 jun. 2012. 14:17:29.

${ }^{5}$ Sistema Nacional de Emprego (SINE).

${ }^{6}$ Disponível em: http://resistir.info/crise/keynes_crise.html Acessado em: jun. 2012.

${ }^{7}$ Disponível em: <http://www.mises.org.br/EbookChapter.aspx?id=118>. Acesso em: 13 abr. 2012. 12:15:59.

${ }^{8}$ Disponível em: $<$ http://libertarianismo.org/livros/celmf.pdf $>$. Acesso em: 02 jul. 2012.

${ }^{9}$ Disponível em: $<$ http://www.epsjv.fiocruz.br/dicionario/verbetes/neosau. html>.Acesso em: 14 jun. 2012. 16:20:30.

${ }^{10}$ Disponível...em: $<$ http://www.ipea.gov.br/desafios/index.php?option=com content $\&$ view $=$ article $\&$ id $=844$ :reportagens-materias $\&$ Itemid $=39>.02$ jul. 2012. 16:12:43.

11 "Os arrendatários proibiam os caseiros de manter, salvo eles próprios, qualquer criatura viva, gado, aves etc...".(A political inquiry into the consequences of enclosing wastelands, Londres, 1785 apud, MARX, 2004, 30). Em outras palavras, se as pessoas são impedidas de viver de subsistência a única forma de manter-se em pé é vender sua força de trabalho para poder comprar a comida que lhe dará forças de manter-se em pé para novamente vender sua força de trabalho.

${ }^{12}$ O Projovem Adolescente - Serviço Socioeducativo é coordenado pelo Ministério do Desenvolvimento Social e Combate à Fome, o Projovem 
Urbano pela Secretaria-Geral da Presidência da República, o Projovem Campo - Saberes da Terra pelo Ministério da Educação e o Projovem Trabalhador pelo Ministério do Trabalho e Emprego. BRASIL. Lei n ${ }^{\circ} 11.662$ de 10 de junho de 2008. Disponível em: http://www.planalto.gov.br/ccivil_03/ Ato2007-2010/2008/Lei/L11692.htm. Acesso em 10 de novembro de 2011.

${ }^{13} \mathrm{Na}$ submodalidade Empreendedorismo Juvenil podem participar os jovens que estejam cursando ou tenham concluído o ensino superior.

${ }^{14}$ BRASIL, Decreto ${ }^{\circ} 6.629$ de 04 de novembro de 2008. Disponível em: https://www.planalto.gov.br/ccivil_03/_ato2007-2010/2008/decreto/d6629. htm. Acesso em 21 de junho de 2012.18:12:28.

${ }^{15}$ Disponível...em: <http://www.ibge.gov.br/home/presidencia/noticias/ noticia_visualiza.php?id_noticia $=1648 \& i d \_p a g i n a=1>$. Acesso em $20 \mathrm{de}$ junho de 2012. 13:13:14.

${ }^{16}$ Hoje (24/06/2012) esse valor é de $\mathrm{R} \$ 2,95$.

${ }^{17}$ RESOLUÇÃO N 194, DE 23 DE SETEMBRO DE 1998 (Revogada pela Resolução n ${ }^{\circ}$ 258/2000). Disponível em: <http://portal.mte.gov.br/data/files/ FF8080812BE914E6012BE9FFAB067CBA/r_19980923_194a.pdf $>$. Acesso em: 03 jul. 2012.

${ }^{18}$ Lima, Júlio César França; Neves, Lúcia Maria Wanderley; Pronko, Marcela Alejandra. Trabalho Simples. Disponível em: $<$ http://www.epsjv.fiocruz.br/ upload/d/Trabalho_Simples_ts.pdf $>$. Acesso em: 02 jul.2012. 17:10:20.

${ }^{19}$ Todos os nomes são fictícios para preservar a identidade dos entrevistados. ${ }^{20}$ Disponível...em: $<$ http://agencia.ipea.gov.br/index.php?option=com_conte nt\&view $=$ article $\&$ id $=12524 \&$ catid $=8 \&$ Itemid $=6>$. Acesso em: 27 jun. 2012. 12:14:58.

${ }^{21}$ Disponível em: <http://www.estadao.com.br/noticias/nacional,educacaoe-pasta-mais-afetada-em-corte-no-orcamento,559625,0.htm>. Acesso em: 29 jun. 2012. 16:23:45.

${ }^{22}$ Disponível em: $<$ http://boitempoeditorial.wordpress.com/category/colunas/ giovanni-alves/>. Acesso em: 15 mar. 12. 15:13:19.

\title{
Referências Bibliográficas
}

\author{
ALVES, Giovani. Capitalismo global, proletariedade e os limites da \\ indignação. Disponível em: <http://boitempoeditorial.wordpress.com/ \\ category/colunas/giovanni-alves/>. Acesso em: 15 mar. 12. 15:13:19.
}


BIELSCHOWSKY, Pablo; CUSTÓDIO, Marcos da Cunha. Keynes: a Crítica ao modelo clássico e a criação da macroeconomia. Revista Eletrônica Novo Enfoque, ano 2011, v. 13, n. 13, p. 62 - 71. Disponível em: $<$ http://www.castelobranco.br/sistema/novoenfoque/files/13/ artigos/6_Prof_Pablo_Marcos_Art3_VF.pdf $>$. Acesso em: 28 abr. 2012. 12:19:19.

CAMPAGNAC, Vanessa. As organizações não-governamentais (ONGs) e o mercado de trabalho.2006. Disponível em: $<$ http://www. abep.nepo.unicamp.br/encontro2006/docspdf/ABEP2006_224.pdf>. Acesso em: 12 mai. 2012. 16:16:13.

COUTINHO, Joana Aparecida. ONGs e políticas neoliberais no Brasil. Florianópolis: Ed. da UFSC, 2011.

FONTES, Virgínia. O Brasil e o capital imperialismo: teoria e história. 3. Ed. Rio de Janeiro: EPSJV/Editora UFRJ, 2010.

FRIEDMAN, Milton. Capitalismo e Liberdade. Disponível em: $<$ http://libertarianismo.org/livros/celmf.pdf $>$. Acesso em: 27 jun. 2012. 17:56:56.

GENTILI, Pablo. Neoliberalismo e educação. In: SILVA, T. T. e GENTILI, P. Escola S. A.: quem ganha e quem perde no mercado do neoliberalismo. Brasília: CNTE, 1996. Disponível em:

$<$ http://barricadasabremcaminhos.files.wordpress.com/2010/06/ neoliberalismo-e-educacao.pdf $>$. Acesso em: 20 jun. 2012. 16:39:56.

HARVEY, David. Condição Pós-moderna (2009). 18 edição, Ed. Loyola, São Paulo/SP.

HAYEK, Friedrich August von. O caminho da servidão. tradução e revisão Anna Maria Capovilla, José Ítalo Stelle e Liane de Morais Ribeiro. - 5. ed. - Rio de Janeiro: Institiuo Liberal, 1990. 221 p. Tradução de: The road to serfdom; 
IASI, Luis Mauro. Ensaios sobre consciência e emancipação. 2.ed. São Paulo: Expressão Popular, 2011;

KEYNES, John Maynard. A Teoria geral do emprego, do juro e da moeda. Ed. Nova Cultural,1996. Círculo do Livro Ltda;

LUCHT, E. ; OREIRO, J. L. C. ; LEMOS, B. P. . Uma Revisão de HPE para o Princípio da Demanda Efetiva. In: EVINCI, 2006, Curitiba. Livro de Resumos do 14 Evinci. Curitiba : Editora da UFPR, 2006. v. 1. Disponível em: <http://www.pet-economia.ufpr.br/banco_de_ arquivos/00009_hpe.pdf >. Acesso em: 25 mai. 2012. 14:18:12.

MARX, Karl. A origem do capital: a acumulação primitiva. Trad: Klaus Von Puchen. São Paulo: Centauro, 2004;

MÉSZÁROS, István. A crise estrutural do capital. 2. Ed. ver e ampliada. Tradução: Francisco Raul Cornejo. São Paulo, Boitempo, 2011.

MISES, Ludwig Von. As seis lições. tradução de Maria Luiza X. de A. Borges. - 6.ed. - Rio de Janeiro: Instituto Liberal. 1998. 98p. Tradução de: Economic policy: thoughts for today and tomorrow. Disponível em:http://www.mises.org.br/files/literature/As\%20Seis\%20 Li\%c3\%a7\%c3\%b5es\%20MISES\%20-\%20WEB.pdf $>$. Acesso em: 03 jul. 2012.

MONTANÕ, Carlos. Terceiro setor e questão social: critica ao padrão emergente de intervenção social. 5.Ed - São Paulo: Cortez, 2008;

MOTA, Ana E. Crise contemporânea e as transformações na produção capitalista. Serviço Social: direitos sociais e competências profissionais. 1 ed. Brasilia: CFESS/ABEPSS, 2009, v. 1, p. 51-68. Disponível em: <http://www.prof.joaodantas.nom.br/materialdidatico/ material/2_Crise_contemporanea_e_as_transformacoes_na_producao_ capitalista_1.pdf $>$. Acesso em: 27 mai. 2012. 12:45:09. 
NOZAKI, Hajime Takeuchi. Globalização, crise do capital e aspectos da formação humana: A Educação Física e o mundo do trabalho. Disponível em: $<$ http://cev.org.br/biblioteca/globalizacao-crise-capitalaspectos-formacao-humana-educacao-fisica-o-mundo-trabalho $>$. Acesso em: 08 jun. 2012. 13:13:19.

RIZZOTTO, Maria Lúcia Frizon. Neoliberalismo e saúde. Dicionário da educação profissional em saúde. Fundação Oswaldo Cruz, 2009. Disponivel em: $<$ http://www.epsjv.fiocruz.br/dicionario/verbetes/neosau. html>.Acesso em: 14 jun. 2012. 16:20:30.

RUMMERT, S. M. A modernização conservadora como marca da educação de jovens e adultos trabalhadores no Brasil. RUMMERT, S. M.; CANÁRIO, R.; FRIGOTTO, G. (Orgs) Políticas de formação de jovens e adultos no Brasil e em Portugal. Niterói: Editora da UFF, 2009. 